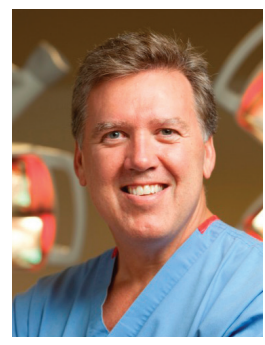

\title{
STEM CELL THERAPY FOR HEART FAILURE
}

\author{
Robert E. Michler, M.D.
}

Montefiore Medical Center, Albert Einstein College of Medicine, New York, New York

R.E. Michler, M.D.

\section{Abstract}

The last decade has witnessed the publication of a large number of clinical trials primarily using bone marrow-derived stem cells as the injected cell. These "first-generation" clinical trials have advanced our understanding and shown us that (1) cell therapy is safe, (2) cell therapy has been modestly effective, and (3) in humans, bone marrow-derived stem cells do not transdifferentiate into cardiomyocytes or new blood vessels (or at least in sufficient numbers to have any effect).

The primary mechanism of action for cell therapy is now believed to be through paracrine effects that include the release of cytokines, chemokines, and growth factors that inhibit apoptosis and fibrosis, enhance contractility, and activate endogenous regenerative mechanisms through endogenous circulating or site-specific stem cells. The new direction for clinical trials includes the use of stem cells capable of cardiac lineage, such as endogenous cardiac stem cells.

\section{The Problem of Heart Failure}

Cardiovascular disease (CVD) is this nation's number-one killer, accounting for $34 \%$ of all U.S. deaths each year, innumerable resources, and healthcare expenditures that approach $\$ 300$ billion annually. ${ }^{1}$ Each year, CVD kills more people than cancer, HIV, diabetes, and trauma combined. ${ }^{2}$ Coronary artery disease (CAD) is the major component of CVD. CAD that results in myocardial infarction (MI) claims more than 1 million U.S. lives each year and leads to countless permanent disabilities including heart failure. ${ }^{1}$

Many advances have been made in the medical and surgical treatment of CAD since the Coronary Artery Surgery Study (CASS) clinical trial identified a fundamental role for surgical intervention. ${ }^{3}$ Cardiac surgery has been central in the treatment of nearly every major cardiac condition. Moreover, the success of medical and surgical therapies in the management of acute and chronic ischemic heart disease has contributed to a growing number of patients reaching their sixth, seventh, and eighth decades of life with congestive heart failure (CHF). Indeed, it is estimated that $1 \%$ of the Western world carries the diagnosis of $\mathrm{CHF}$, and approximately 5 million Americans currently live with heart failure, with an additional 400,000 patients newly diagnosed each year. ${ }^{4} \mathrm{CHF}$ is the most common admitting diagnosis for patients over the age of 65 years and is associated not only with a decreased quality of life but also significant mortality. ${ }^{5}$ The age-adjusted mortality rate for CHF is 106 per 100,000, exceeding that of breast cancer and AIDS combined. Recent data suggest that $\mathrm{CHF}$ carries a mortality rate of at least $40 \%$ within 2 years of diagnosis. For those patients with the most advanced stages of CHF (New York Heart Association class IV), the 1-year mortality rate exceeds $50 \%$. In addition to its poor prognosis, the treatment of $\mathrm{CHF}$ is associated with very high and continuingly escalating costs. Not only is CHF the most expensive diagnosis-related group covered by Medicare and Medicaid, it is estimated that the total medical costs associated with the treatment of CHF exceed \$29 billion per year. ${ }^{6-8}$

Heart transplantation is considered to be the gold standard for the treatment of advanced end-stage $\mathrm{CHF}$, and more than $50 \%$ of transplant patients survive 10 years. ${ }^{9}$ Quality of life after cardiac transplantation improves greatly, as does exercise capacity and freedom from hospitalization. Unfortunately, this is an epidemiologically inconsequential therapy, with the low number of available donor hearts too few to meet the demand. As if the unmet need for heart transplantation among eligible patients were not enough, many CHF patients are ineligible for transplantation and remain without a viable medical, percutaneous, or surgical treatment option. These ineligible patients include those with diffuse small-vessel CAD, in-stent restenosis, chronic total occlusions, and degenerated vein grafts. It has been estimated that more than 100,000 patients in the United States each year may be in this "no-option" group..$^{10}$

\section{The Rationale for Regenerative Surgery}

The treatment of postinfarction heart failure remains an elusive goal in medicine. One novel evolving therapeutic strategy for advanced ischemic heart disease is regenerative surgery, the transplantation of immature progenitor cells into the damaged heart with the expectation that these cells will produce new blood vessels and cardiac muscle cells. The past decade has witnessed a surge of scientific enthusiasm for regenerative surgery that has resulted in multiple clinical trials to treat the failing human heart.

To understand the foundation of regenerative surgery, one must first understand that the heart has traditionally been viewed as a terminally differentiated organ, unable to regenerate new cardiomyocytes. This important theory of the past 50 years ${ }^{11}$ has now been overturned by the findings of multiple investigators. ${ }^{12}$ Through carbon dating, it is now known that approximately $1 \%$ 
of cardiomyocytes are replaced each year, and approximately 40\% of the myocytes in a mature human heart are of postnatal origin. This discovery has raised the expectation that the heart may be coaxed into regenerating muscle cells and large-caliber conductive coronary arteries when injured. Why repair does not occur following a myocardial infarction remains a mystery and is actively being investigated by research scientists.

Investigative evidence from multiple animal experiments has demonstrated that the transplantation of certain specific stem cells can produce new cardiomyocytes and coronary blood vessels. These findings have dramatically altered the course of cardiovascular research. Importantly, these investigations have also demonstrated that angiogenesis and cardiogenesis are complex and still poorly understood processes, requiring precise conditions, growth factors, and probably specific progenitor cell phenotypes and cell numbers. ${ }^{13}$ Of course, the enthusiasm generated by these animal experiments led to clinical trials evaluating whether stem cells could form new cardiac muscle and blood vessels in the damaged hearts of humans. Many investigative hurdles have been considered, not least of which are the ideal cell phenotype, cell preparation techniques, the delivery method, the number of cells that need to be injected in order to provide benefit, the timing of the administration of cell therapy, and the particular microenvironment or clinical condition into which the cells are delivered. A typical MI kills several grams of myocardial tissue, and each gram of heart muscle is estimated to contain approximately 20 million cardiomyocytes. To date, the number of stem cells that would need to be injected to regenerate an area of infarction remains unclear and is a topic of intense speculation.

More than 3,000 patients worldwide have been enrolled in clinical trials involving bone marrow cells. The majority of these "first-generation" clinical trials have involved some form of bone marrow-derived cell, which has held great promise despite the unambiguous knowledge that these cells do not normally form cells of cardiac origin. It has been widely held that these cells could perhaps be coaxed in humans, as they occasionally have been in rodents, to form cardiomyocytes and blood vessels. Results from these clinical studies have not yielded the hoped-for results, and, in fact, these studies have been largely disappointing with modest, transient, and inconsistent improvement in symptoms, left ventricular (LV) function, and LV geometry. Nevertheless, these first-generation clinical trials have been very informative. Most importantly, cell therapy has been shown to be feasible and safe. The mechanism is unclear for the modest benefit in humans, and there is no evidence to date of true cellular regeneration in humans - that is, the development of new cardiomyocytes or new blood vessels that unequivocally have arisen from transplanted stem cells. Whatever clinical benefit has been seen is likely the consequence of paracrine effects resulting from the release of cytokines, chemokines, and growth factors, which activate endogenous reparative mechanisms, inhibit apoptosis and fibrosis, and enhance contractility.

These clinical lessons are important because they help focus the goal of stem cell therapy. Is the objective to create new blood vessels and heart muscle or a catalyst and appropriate microenvironment for endogenous reparative mechanisms to flourish? The latter goal has been demonstrated to some degree through these firstgeneration clinical trials, and further refinements may prove to be more fruitful.

On the other hand, a number of the newer-generation clinical trials utilize specific cell types known to produce cardiac lineage cells. The majority of first-generation trials using bone marrow cells focused on the repair of acute or chronic myocardial damage resulting from infarction. However, each clinical scenario, acute infarction, chronic ischemia and chronic heart failure (ischemic and nonischemic) are different with respect to their local vascular, cellular, and chemical microenvironments, thus requiring the clinician scientist to optimize the local conditions at the time of cell delivery to enhance engraftment and benefit. Experienced-based decisions must now focus on identifying optimum cell dose, timing of administration, method of delivery, and the specific clinical disease to be treated with the desired cell therapy regimen.

It is reasonable to anticipate that cellular therapies for ischemic heart disease will need to address two important considerations: (1) the development of a network of capillaries and large conductive blood vessels to supply oxygen and nutrients to both the chronically ischemic myocardium and the newly implanted progenitor cells, and (2) the release or administration of factors capable of paracrine signaling to nourish the administered stem cells. The following addresses our present understanding of the multiple cell types and lessons learned from clinical trials of myocardial regenerative surgery.

\section{Types of Stem Cells}

Stem cells are defined as having specific characteristics. They are undifferentiated cells that are self-renewing, clonogenic (i.e., form identical clones), and multipotent, or able to differentiate into a wide array of specialized cell types. Stem cells can be categorized in a number of ways: anatomically, functionally, or by cell surface markers, transcription factors, and protein expression. The simplest and most common basic grouping of stem cells is based on their site of origin. Stem cells isolated from the embryo are named embryonic stem cells (ESCs), and stem cells isolated from the adult are known as adult stem cells (ASC) (Figure 1).

\section{Embryonic Stem Cells}

Embryonic stem cells are totipotent cells that possess the ability to differentiate into cells derived from the three germ layers:

\section{Regenerative Surgery: Undifferentiated Cells for Myocardial Regeneration Self Renewing, Clonogenic, Multipotent}

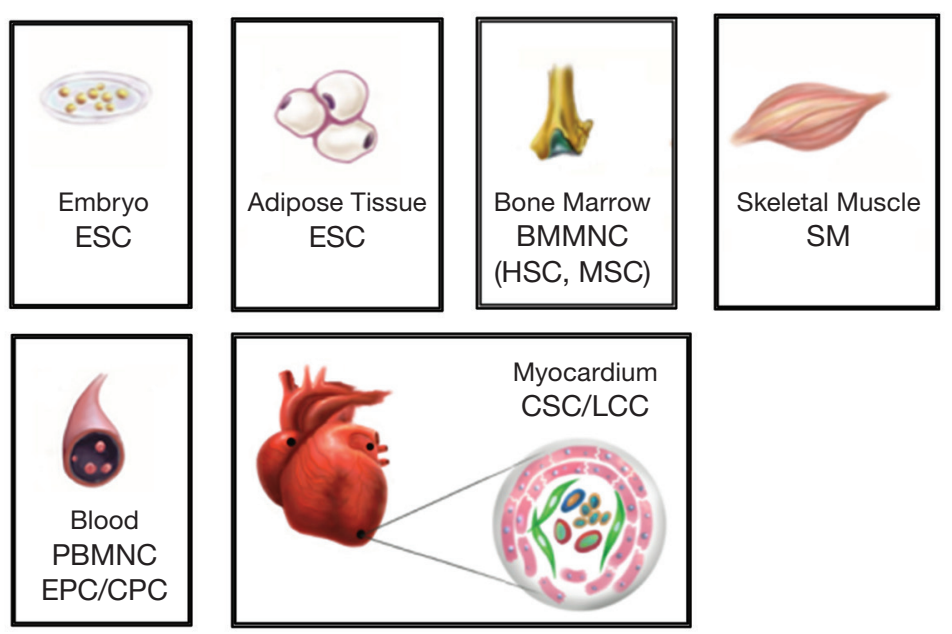

Figure 1. The portfolio of cells considered for regenerative surgery and their unique characteristics. 
ectoderm, endoderm, and mesoderm. ESCs are derived from the inner cell mass of the blastocyst of a 3- to 5-day old embryo. First isolated from murine blastocysts by Evans, Kaufman, and Martin in 1981, ESCs have been shown to grow for an indefinite period in vitro while maintaining the potential to differentiate into derivatives of all three embryonic germ layers. Thompson developed the first successful ESC line, opening the field of stem cell research. ESCs have been shown to be capable of generating functional cardiac, neuronal, and pancreatic cells in animal and human models. Irrespective of their enormous regenerative potential, however, ESCs are enveloped in controversy and medical ethics related to their source of origin in humans as well as their malignant degenerative potential. Therefore, to date, no clinical studies have been initiated in humans for cardiac repair.

\section{Adult Stem Cells}

Adult stem cells, when compared to embryonic stem cells, have less potent self-renewal ability, and the types of cells that can be created through transdifferentiation are fewer. Despite these limitations, a variety of ASC populations have been explored with the expectation of finding an effective therapeutic candidate for regenerative surgery. Since ASCs reside in the postnatal bone marrow, blood, skeletal muscle, fatty tissue, and heart of humans, harvesting these cells for clinical application may be more straightforward.

\section{Skeletal Myoblasts}

The regenerative capacity of skeletal muscle is well established. Mauro in 1961 described the first skeletal muscle "satellite" cells. ${ }^{14}$ What we now know is that every mature skeletal muscle fiber contains a small number of undifferentiated and inactive satellite cells known as myoblasts. Skeletal myoblasts remain in a quiescent state until the muscle fiber is damaged. When injury occurs, these cells rapidly proliferate and fuse with one other and with the injured muscle cell, restoring continuity of the entire muscle fiber. The ability of the myoblast to proliferate and differentiate into muscle fibers, as well as replace and therefore regenerate injured or dying skeletal muscle cells, leads to the natural intellectual question of whether these satellite cells could repair the damaged heart.

In addition, there are unique advantages to the skeletal myoblast as a regenerative option. Skeletal myoblasts are readily available, have greater capacity to withstand ischemia, and are relatively straightforward to harvest, resulting in a potentially suitable cell candidate for cellular transplantation. ${ }^{15}$ On the other hand, skeletal muscle cells under normal conditions are not capable of continuous, repetitive, high-frequency, and synchronous contractions that are the hallmark of the functioning cardiac muscle. It has never been demonstrated that skeletal myoblasts can function analogous to the myocardium in vivo. Therefore, the most significant clinical problem with skeletal myoblasts is that they remain electrically and mechanically uncoupled from the host myocardium.

\section{Summary of Clinical Trials with Skeletal Myoblasts}

Human clinical trials with skeletal myoblasts were primarily conceived and conducted by Menasche. In several single-center and multicenter clinical trials, he and others demonstrated myoblast engraftment and that adverse ventricular remodeling could be attenuated by skeletal myoblast transplantation. ${ }^{15,16}$

In the multicenter study, 97 subjects received injections of native cultured autologous myoblasts (harvested from a skeletal muscle biopsy) into the epicardial surface and around the area of infarction at the time of coronary artery bypass surgery. ${ }^{17}$ After a 4-year follow-up, implantation of skeletal myoblasts into myocardial scar tissue was believed to have resulted in some benefit as demonstrated by increased fluorodeoxyglucose (FDG) on PET scan, by an increase in area of tissue viability by MRI, or by the improvement of left ventricular ejection fraction (LVEF) on echocardiogram. However, a significant safety concern was raised by the development of ventricular arrhythmias.

Collectively, these studies demonstrate that cellular cardiomyoplasty with skeletal myoblasts is modestly effective in preventing deterioration of ventricular geometry and cardiac function in clinical trials of ischemic cardiomyopathy. This therapy has limited clinical potential and is hampered by the concern for arrhythmias. At this time, it is unlikely to be considered a primary choice for cardiac therapeutic interventions.

\section{Bone Marrow Cells}

Human bone marrow is composed of cells and an extracellular matrix that contains cytokines and growth factors. ${ }^{18}$ The cellular component of bone marrow is composed of differentiated cells, such as monocytes, lymphocytes, fibroblasts, adipocytes, chondroblasts, osteoblasts, and osteoclasts, as well as a fractionally small but very diverse group of undifferentiated cells. The undifferentiated stem cell population is composed of hematopoietic stem cells (HSC), which include hemangioblasts and endothelial progenitor cells (EPC), and nonhematopoietic mesenchymal precursor cells (MPCs) that give rise to stromal cells referred to as mesenchymal stem cells (MSCs). The undifferentiated stem cell population can be isolated from differentiated cells by density gradient centrifugation. The end product of this centrifugation process is referred to as bone marrow mononuclear cells (BMMNC) and contains the undifferentiated HSC and MSC as well as a few committed cells in various stages of maturation. The overall structure of BMMNC is primarily that of early committed cells, with only $2 \%$ to $4 \%$ comprised of HSC/EPC and approximately $0.01 \%$ of MSC. ${ }^{19}$

In humans, HSC express cell surface antigens CD31, CD34, CD45, CD133, and KDR and are lineage negative (Lin_) and CD38 negative. ${ }^{20-22}$ Mesenchymal stem cells, in contrast, do not express hematopoietic lineage markers and therefore do not produce hematopoietic lineages. Mesenchymal stem cells give rise to adipocytes, chondroblasts, and osteoblasts. They uniquely adhere to plastic in cell culture and are characterized primarily by the cell surface antigens CD90 and CD105, but they also will express CD17, CD29, CD44, CD106, CD120a, and CD124. Mesenchymal stem cells are negative for CD31, CD34, CD45, CD133, CD14(CD11b), CD19, and KDR; they are also HLA-DR negative and therefore are believed to evade immune recognition. ${ }^{23,24}$

Mesenchymal stem cells represent a very small fraction of the total bone marrow mononuclear stem cell population, ranging from $0.001 \%$ to $0.01 \%$ of the total population. This translates into approximately 2 to 5 MSCs per $1 \times 10^{6}$ mononuclear cells. ${ }^{23,25}$ They release cytokines and growth factors that can stimulate endogenous repair mechanisms. ${ }^{26}$ Although MSCs are primarily thought to arise from bone marrow, other tissues and organs may also produce cells of the MSC phenotype. These organs include the heart, blood, brain, liver, testis, prostate, skeletal muscle, and fatty tissue.

Undifferentiated BMMNCs (HSCs and MSCs) do not normally contribute to cardiac lineage cells. Mesenchymal stem cells give rise to adipocytes, chondroblasts and osteoblasts, and HSCs normally give rise to endothelial cells and all hematopoietic lineages. ${ }^{27,} 28$ However, under specific microenvironmental conditions, HSCs have been shown, in vitro and in select rodent 
animal models of injury, to transdifferentiate into a wide variety of phenotypes including skeletal muscle, ${ }^{29}$ neurons, ${ }^{30}$ hepatocytes, ${ }^{31}$ and possibly cardiomyocytes. ${ }^{32}$ It remains controversial whether these hematopoietic bone marrow lineage cells are truly able to transdifferentiate into cardiomyocytes and whether this will ever be feasible in the clinical arena.

As with HSCs, MSCs under specific microenvironmental conditions can be induced in vitro to transdifferentiate into skeletal and cardiac muscle $\mathrm{e}^{23,33,34}$ and have been shown under uniquely precise conditions to transdifferentiate into cardiomyocytes in an in vivo rodent animal model. ${ }^{35,36}$ Toma et al. demonstrated the ability of human MSCs to differentiate into cardiomyocytes when injected into the murine myocardium. ${ }^{35}$ Mangi et al. injected genetically modified autologous MSCs into the ischemic rat myocardium. ${ }^{37}$

\section{Summary of Clinical Trials with Bone Marrow Cells}

To date, the majority of human stem cell clinical trials have involved cells of bone marrow origin. Bone marrow is readily available and therefore an easily accessible source of multipotent cells. When the first bone marrow human clinical trials were proposed, many hospitals with prior experience harvesting bone marrow for transplantation were eager to proceed with these trials. This zealousness drove the approval process for protocols by hospital Institutional Review Boards despite limited evidence of proven benefit in animal models. Now, many years later, these trials can be summarized as having resulted in modest, inconsistent, and transient improvements in clinical endpoints. Nevertheless, these trials have demonstrated the safety and feasibility of stem cell therapy and fueled the desire to pursue further clinical studies.

Although washed whole bone marrow has been used in human clinical trials, many investigators believe that this is less than ideal since the undifferentiated stem cells exist in such small numbers that they are unlikely to be effective. The cellular component of bone marrow contains differentiated cells such as monocytes, lymphocytes, osteoblasts, and osteoclasts and a small but very diverse group of undifferentiated cells. It is this latter group of undifferentiated cells, the hematopoietic and the nonhematopoietic or mesenchymal stem cells, that are capable of multipotent differentiation and, what many hope, will lead to the development of new heart muscle and blood vessels.

The total number of stem cells residing in the bone marrow of humans at any given time is insufficient for significant organ repair. Bone marrow aspiration, isolation, selection of a specific cell phenotype, and in vitro expansion may be required to achieve sufficient quantities of cells for successful therapy. Importantly, unlike HSC, MSCs lack major histocompatibility complex antigens and thus can evade immunological detection and subsequent rejection by the host. Mesenchymal stem cells have been shown to function normally after preservation by freezing. ${ }^{38-40}$ Therefore, MSC could potentially serve as an allogeneic graft, thereby avoiding the need for bone marrow harvesting from individual prospective recipients, an extraordinary therapeutic advantage. Commercial manufacture of these cells is now in progress and available for use in select clinical trials. Both HSCs and MSCs can be separated from the bone marrow mononuclear cell fraction by gradient centrifugation and immunoselection using a good manufacturing practice (GMP) grade monoclonal antibody specific for surface markers expressed on either hematopoetic or mesenchymal precursors. Allogeneic mesenchymal stem cells are cultured under GMP conditions in media supplemented with fetal bovine serum, grown to a master cell bank stage, and subsequently expanded prior to lot release for use in human trials.

The many completed human clinical trials are noteworthy in that they have delivered either mixed or enriched bone marrow cells, administered different total numbers of cells and different numbers of specific HSCs or MSCs, and infused cells at varying time intervals after myocardial injury, all of which have made comparing and interpreting the results of these trials challenging. It is important to emphasize that in all of the trials in which cells were harvested the same day or within a few days of delivery, there is insufficient time to select, culture, and expand specific cell populations into large numbers for infusion. With a timetable of a few days, it is only possible to select for specific phenotypes that can be administered in small numbers. Therefore, in the majority of trials, especially those in which the bone marrow was harvested and delivered on the same day, the cells infused were a heterogeneous population of bone marrow cells that included MSCs, stromal cells, and hematopoietic progenitor cells. The authors may report the specific percentage of the infused cells containing specific stem cell phenotypic markers for hematopoietic progenitor cells (e.g., CD34+) or MSCs (e.g., CD105+), but these cells are present in small numbers compared to the total cells delivered and, therefore, are mixed together with other bone marrow cells.

While some human studies have demonstrated modest improvement in left ventricular (LV) function and, occasionally, attenuation of LV dilation (reverse remodeling), no study has yet to document true myocardial regeneration with the development of new cardiac myocytes or new blood vessels originating from the administered cells. Additionally, these trials have been conducted in patients with a wide range of ischemic heart disease, from acute infarction to chronic ischemic heart failure, which adds to the difficulty of interpreting results with respect to selecting the best bone marrow stem cell. Many believe that the underlying disease state will influence the selection of the best stem cell for that condition, and there is growing evidence to support the fact that the acuity of the heart disease and the medical condition of the patient may actually influence the quality and numbers of bone marrow stem cells yielded at harvest. Interpretation of clinical trial results requires the careful segregation of cell types and disease states, which, unfortunately, dilutes the total number of patients that are available for analysis of a specific cell type and cell preparation.

In most BMMNC studies, the cells were infused early after MI and usually within days of an MI. Originally, this had been considered an optimum time interval for recovery based on the expected presence of a reparative microenvironment induced by the MI. Recent evidence suggests that although the microenvironment elaborates cytokines, growth factors, and chemokines that promote cell homing and engraftment, it also elaborates inflammatory agents and other destructive chemicals that produce the opposite effect. If we compare studies in which the cells were administered early $(<7$ days $)$ and late $(>2$ weeks) after an acute MI, we find very little difference between treatment groups with respect to an improvement in LVEF. In the REPAIR-MI trial, the improvements in LVEF (mean 5.5\% vs. $3 \%$ ) were seen with cell application 3 to 6 days post-acute MI. This is in contrast to the results of the SWISS-MI study and both TIME trials performed by the Cardiovascular Cell Therapy Network (CCTRN), in which all three studies showed no improvement in LVEF with the administration of BMMNC 
at any time point. The TIME trial ${ }^{41}$ evaluated unselected BMMNC therapy 3 days versus 7 days after an acute anterior-wall ST elevation MI in 120 patients with LVEF $<45 \%$ who were successfully treated with primary percutaneous coronary intervention (PCI). BMMNCs were administered within 12 hours of aspiration and cell preparation. The LATE TIME trial ${ }^{42}$ evaluated BMMNC infusion at 2 to 3 weeks after an acute anterior-wall ST elevation MI versus placebo in 87 patients with LVEF $<45 \%$ who were successfully treated with primary PCI. BMMNCs were administered within 12 hours of aspiration and cell preparation. No significant improvement in LVEF measured at 6 months was seen in either TIME trial, even in the subgroup with the most depressed LV function. The SWISS-MI trial provided a direct prospective comparison between early and late administration of BMMNC and failed to demonstrate a significant benefit in either group. Importantly, in these recent trials, cardiac magnetic resonance (CMR) was used to assess LV function since it is presently considered to be the best imaging modality available to evaluate LV function and geometry. In addition, the marginal benefit in LV function seen with BMMNCs has also been described in several recent meta-analyses of clinical trials and, specifically, in clinical trials using CMR to evaluate the benefit of BMMNC after MI. ${ }^{42,43}$

Jeevanantham reviewed a total of 50 publications enrolling 2,625 patients in clinical trials through January 2012. Compared with control subjects, BMMNC-treated patients exhibited a very modest and probably clinically irrelevant improvement in LVEF $(3.96 \%$; 95\% confidence interval, 2.90-5.02; $\mathrm{P}<0.001)$, smaller infarct size $(-4.03 \%$, $95 \%$ confidence interval, -5.47 to $-.59 ; \mathrm{P}<0.001)$, LV end-systolic volume $(-8.91 \mathrm{~mL} ; 95 \%$ confidence interval, -11.57 to $-6.25 ; \mathrm{P}<0.001)$, and LV end-diastolic volume $(-5.23 \mathrm{~mL}$; $95 \%$ confidence interval, -7.60 to $-2.86 ; \mathrm{P}<0.001)$. These statistically significant but marginal clinical benefits were evident irrespective of the type of ischemic heart disease (acute MI vs. chronic ischemic heart disease). Although these trials were not designed or powered to assess secondary endpoints, it is important to recognize that all-cause mortality, cardiac mortality, and the incidence of recurrent MI were better in cell therapy patients compared to control subjects. These findings have certainly stimulated the interest in pursuing additional and larger-scale clinical trials.

By now, it is apparent that the current results for stem cell therapies with bone marrow-derived cells are highly variable and inconsistent, providing only mild to modest benefit in LV function and geometry and a duration of benefit that is most often shortlived and often transient. The reasons for these discrepant results are multiple, probably partly discernible and certainly partly indecipherable, but without question deserving of our attention. In general, the technique for cell preparation is variable, as is the incubation period for selection and expansion. Some cells are injected on the same day of harvest while others delay a day or more. The exact nature of the injectate is unclear and most often heterogeneous. The number and phenotype of the cells injected are not always reported, and, when reported, the total number of cells injected varies from study to study and often patient to patient within a study. Finally, the delivery technique is variable, the timing of delivery is inconsistent, the extent of LV dysfunction and geometry is variable, and the follow-up time is often only a matter of months.

\section{Endogenous Cardiac Stem Cells}

Multipotent, clonogenic, and self-renewing cardiac stem cells (CSCs) exist within the myocardium and were first identified by Anversa and colleagues in 2003. ${ }^{12}$ These cells give rise to cardiomyocytes, smooth muscle cells, and endothelial cells in animal models of ischemia. ${ }^{44}, 45$ Cardiac stem cells are characterized by the stem cell antigen c-kit, cell surface antigens Sca-1 and MDR1, and do not express the hematopoietic surface antigens CD31, CD34, CD45, CD133, and KDR. Cardiac stem cells are distinct from circulating endothelial progenitor cells (CPC) that arise in the bone marrow and migrate to the myocardium. Circulating endothelial progenitor cells are also c-kit positive, but unlike CSCs, express KDR and hematopoietic cell surface markers CD31 and CD45.

Cardiac stem cells reside in myocardial niches, where they divide and differentiate. Stem cell niches are distributed throughout the heart, with the LV apex and atrial tissue appearing to be the most densely populated locations. They participate in the normal turnover of cardiac cells by forming new myocytes and capillaries. ${ }^{46}$ Although limited in number, there is 1 CSC per 8,000 to 20,000 myocytes, and the cells are powerful enough to generate nearly $3 \times 10^{6}$ cardiomyocytes a day in the fully functional and healthy heart. Considering an equal number of cells decreasing each day due to apoptosis/necrosis, it is now believed that the myocardium replaces a large proportion of its cell population about every 5 years. ${ }^{47}$

Despite its regenerative potential, the heart appears unable to defend itself adequately against ischemic or nonischemic injury. The reasons for this limited endogenous reparative ability remain unclear and are likely to include the following: the ischemic insult affects the CSC population as well as native myocytes and endothelial cells; the number of c-kit+ CSCs within the myocardium decreases with age, and therefore the regenerative potential decreases; and, CSCs have a limited ability to translocate and home to an area of injury. ${ }^{46,} 48,49$

In a dog model of orthotopic heart transplantation, our group demonstrated that CSCs isolated and explanted from the native recipient hearts generate immunocompatible cardiomyocytes and supporting neovasculature when injected into the coronary arteries of the transplanted donor hearts (Figures 2 and 3). ${ }^{50}$ This novel model for investigation of stem cell therapy demonstrated the feasibility of regenerating myocardium on a transplant allograft
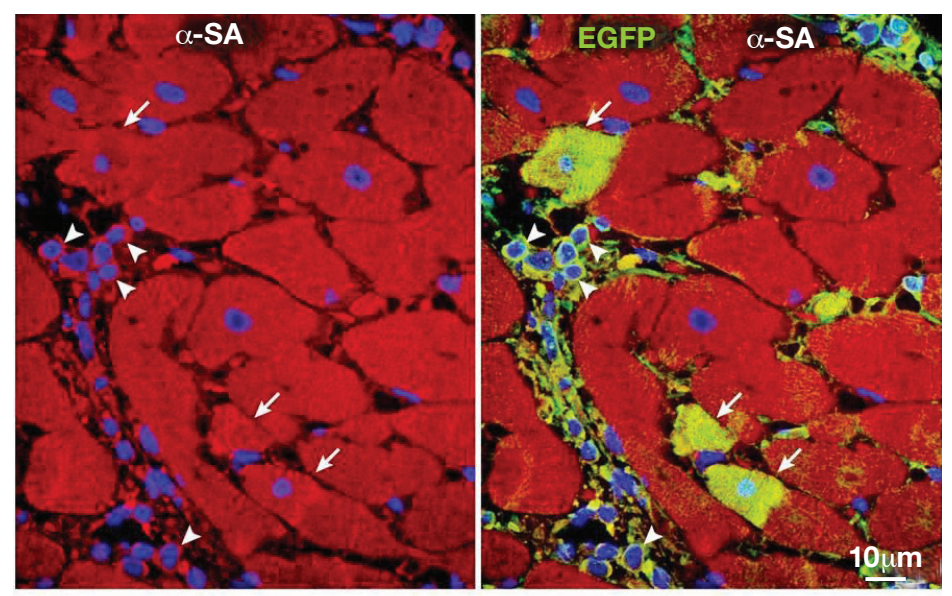

Myocardial Regeneration: Differentiated and developing cells are indistinguishable from native mayocardium

Figure 2. This figure provides evidence supporting myocardial regeneration in a dog transplant model. The EGFP-stained cells in the right panel are indistinguishable on the left panel from the surrounding native donor heart myocardium. These EGFP-positive cells are of recipient origin and demonstrated to be electrically and mechanically coupled to the native donor myocardium. ${ }^{13}$ 


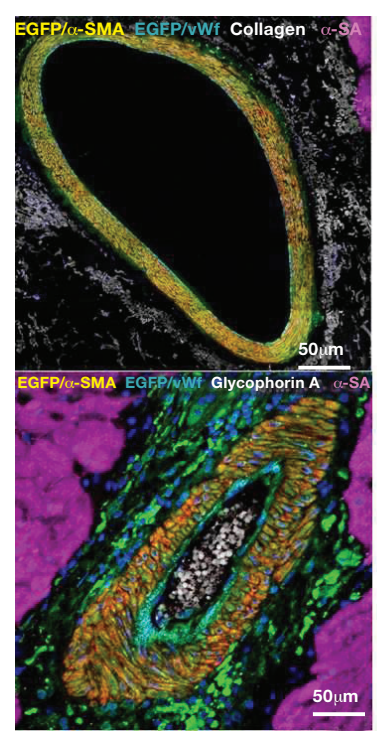

\section{Neovascularization}

Coronary Vessels

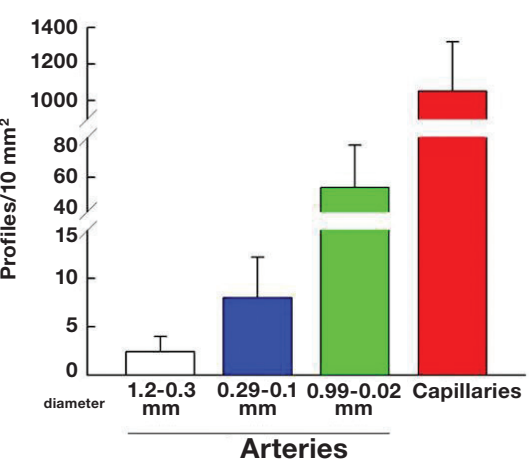

Figure 3. This figure provides evidence supporting blood vessel regeneration in a dog transplant model. The EGFP-positive cells are of recipient origin and contain medium to large caliber arteries. ${ }^{13}$

scaffold in an immunosuppressed host. Such therapy could provide a potent new therapy for the maintenance and treatment of transplanted hearts. Repeated therapeutic injections of autologous CSCs might create a progressive chimerism, reducing the incidence and clinical severity of rejection, and result in an organ increasingly resistant to immune-mediated injury and the ravages of accelerated graft atherosclerosis. Cardiac stem cell therapy could have a transformative effect on cardiac transplantation and become a potent clinical laboratory for stem cell biology.

Marban and colleagues have described a related endogenous cardiac progenitor cell, the "cardiosphere." Cardiosphere-derived cells are a naturally occurring mixed population of stem cells comprising endogenous CSCs (c-Kit+) and cardiac MSCs (CD90+ and CD105+) but not HSCs (CD45-). They are grown under very specific conditions. Cardiospheres are clonogenic, self-renewing, and exhibit multilineage potential. ${ }^{51,52}$ Smith and colleagues described the feasibility and safety of isolation and expansion of adult CSCs from human endomyocardial biopsy specimens. ${ }^{53}$

\section{Selected CSC Clinical Trials}

SCIPIO was the first human, phase 1, randomized, open-label clinical trial to evaluate autologous c-kit+ CSCs in patients with ischemic heart failure (LVEF $\leq 40 \%$ ) who were roughly 3.7 years post-MI. The initial 16-patient CSC-treated group has been expanded to 20 patients. A total of 33 patients (20 CSC-treated and 13 control subjects) received intracoronary infusion of $1 \times 10^{6}$ cells a mean of 113 days after coronary artery bypass surgery (CABG). Cardiac stem cells were harvested from the right atrial appendage during CABG surgery.

In the CSC-treated patients, CMR showed an increase in LVEF (from $27.5 \% \pm 1.6 \%$ to $35.1 \% \pm 2.4 \%$ [P $=0.004, \mathrm{n}=8]$ and $41.2 \%$ $\pm 4.5 \%[\mathrm{P}=0.013, \mathrm{n}=5]$ at 4 and 12 months after CSC infusion, respectively). Infarct size decreased after CSC infusion by $-9.8 \pm$ $3.5 \mathrm{~g}$ at 12 months in 6 patients who completed a 1-year follow-up. Left ventricular nonviable mass decreased by $-14.7 \pm 3.9 \mathrm{~g}$, and $\mathrm{LV}$ viable mass increased by $+31.5 \pm 11.0 \mathrm{~g}$ at 12 months in these same patients. The authors concluded that the improvements in LVEF, viable mass, and nonviable LV mass were seen at 4 months and persisted to 12 months in a subgroup of patients and were consistent with cardiac regeneration.

Marban and coworkers evaluated cardiosphere-derived cell infusion in a prospective, randomized human clinical trial (CADUCEUS) of patients with ischemic LV dysfunction (LVEF $25 \%-45 \%$ ) who had experienced an MI and were successfully treated by $\mathrm{PCI} /$ stent. A total of 17 patients randomly received 12.5 to $25 \times 10^{6}$ autologous cardiospheres grown from endomyocardial biopsy specimens infused into the infarct-related artery $\leq 90$ days after MI. These cardiosphere-treated patients were compared to eight patients who were randomly assigned to receive standard of care. Compared with controls at 6 months, MRI analysis of patients treated with cardiospheres showed no improvement in end-diastolic volume, end-systolic volume, or LVEF. However, reductions in scar mass $(\mathrm{P}=0.001)$, increases in viable heart mass $(P=0.01)$, and regional systolic wall thickening $(P=0.015)$ were seen at 6 months. These authors noted that the increase in viable myocardium, consistent with therapeutic regeneration, merit further investigation in a phase II clinical trial.

\section{Summary}

The last decade has witnessed the publication of a large number of clinical trials, primarily using BMMNC as the injected cell, that often were produced by different techniques, delivered in different doses via multiple routes of administration, and evaluating patients chiefly with acute MI but also those with chronic ischemia and ischemic and nonischemic heart failure. It is no wonder that the field has been viewed as confusing to interpret, producing conflicting information regarding mechanism of action, ideal cell type, cell dose, route and timing of delivery, clinical indications, and clinical effectiveness. Despite this perspective, these "firstgeneration" clinical trials have advanced our understanding of stem cell use. Research has shown that (1) cell therapy is safe; (2) cell therapy has been modestly effective; (3) BMMNCs in humans do not transdifferentiate into cardiomyocytes or new blood vessels (or at least in sufficient numbers to have any effect); (4) insufficient numbers of cells have been injected with poor early retention $(<10 \%$ at 24 hours) and poor engraftment ( $<1 \%$ at 4 weeks); (5) molecular homing signals are disrupted or dyssynchronous; and (6) there is often an abnormal extracellular matrix at the site of tissue injury.

The primary mechanism of action for cell therapy is now believed to be through paracrine effects that include the release of cytokines, chemokines, and growth factors that inhibit apoptosis and fibrosis, enhance contractility, and activate endogenous regenerative mechanisms through endogenous circulating or sitespecific stem cells. The new direction for clinical trials includes the use of stem cells capable of cardiac lineage, such as endogenous CSCs, priming with molecular homing signals, genetically engineering stem cells to express cardiac lineage or chemokines and growth factors, and the application of biomaterials to support a disrupted extracellular matrix. A promising area of stem cell therapy for cardiac repair is the use of enriched stem cell populations such as CSCs and cardiospheres.

Cardiovascular disease and its relentless progression to heart failure requires inspired and dedicated physician innovators to create new evidence-based knowledge to improve both shortand long-term clinical outcomes and abate the relentless death march of heart failure. We should expect that through continuing collaborative efforts combining insights derived from animal studies and well-designed clinical trials, multipotent cells will be a useful and effective part of the clinical armamentarium to treat heart disease. 
Conflict of Interest Disclosure: The author has completed and submitted the Methodist DeBakey Cardiovascular Journal Conflict of Interest Statement and none were reported.

Funding/Support: The author has no funding disclosures.

Keywords: stem cell therapy, regenerative medicine, heart failure

\section{References}

1. Roger VL, Go AS, Lloyd-Jones DM, Benjamin EJ, Berry JD, Borden WB, et al. Executive summary: heart disease and stroke statistics - 2012 update: a report from the American Heart Association. Circulation. 2012 Jan 3;125(1):188-97.

2. Murphy SL, Xu JQ, Kochanek KD. Deaths: Preliminary Data for 2010. Natl Vital Stat Rep. 2012 Jan 11;60(4):1-52.

3. Killip T, Passamani E, Davis K. Coronary artery surgery study (CASS): a randomized trial of coronary bypass surgery. Eight years follow-up and survival in patients with reduced ejection fraction. Circulation. 1985 Dec;72(6 Pt 2):V102-9.

4. Miller LW, Missov ED. Epidemiology of heart failure. Cardiol Clin. 2001 Nov;19(4):547-55.

5. Roger VL, Go AS, Lloyd-Jones DM, Adams RJ, Berry JD, Brown TM, et al.; American Heart Association Statistics Committee and Stroke Statistics Subcommittee. Heart disease and stroke statistics - 2011 update: a report from the American Heart Association. Circulation. 2011 Feb 1;123(4):e18-e209.

6. Baumgartner WA, Burrows S, del Nido PJ, Gardner TJ Goldberg S, Gorman RC, et al. Recommendations of the National Heart, Lung, and Blood Institute Working Group on Future Direction in Cardiac Surgery. Circulation. 2005 Jun 7;111(22):3007-13.

7. O'Connell JB, Bristow MR. Economic impact of heart failure in the United States: time for a different approach. J Heart Lung Transplant. 1994 Jul-Aug;13(4):S107-12.

8. Thom T, Haase N, Rosamond W, Howard VJ, Rumsfeld J, Manolio T, et al. Heart disease and stroke statistics--2006 update: a report from the American Heart Association Statistics Committee and Stroke Statistics Subcommittee. Circulation. 2006 Feb 14;113(6):e85-151.

9. Terrovitis JV, Bulte JW, Sarvananthan S, Crowe LA, Sarathchandra P, Batten $\mathrm{P}$, et al. Magnetic resonance imaging of ferumoxide-labeled mesenchymal stem cells seeded on collagen scaffolds-relevance to tissue engineering. Tissue Eng. 2006 Oct;12(10):2765-75.

10. Lenzen MJ, Boersma E, Reimer WJ, Balk AH, Komajda M, Swedberg K, et al. Under-utilization of evidence-based drug treatment in patients with heart failure is only partially explained by dissimilarity to patients enrolled in landmark trials: a report from the Euro Heart Survey on Heart Failure. Eur Heart J. 2005 Dec;26(24):2706-13.

11. MacLellan WR, Schneider MD. Genetic dissection of cardiac growth control pathways. Annu Rev Physiol. 2000;62:289-319.

12. Beltrami AP, Barlucchi L, Torella D, Baker M, Limana F, Chimenti $S$, et al. Adult cardiac stem cells are multipotent and support myocardial regeneration. Cell. 2003 Sep 19;114(6):763-76.

13. Asahara T, Bauters C, Zheng LP, Takeshita S, Bunting S, Ferrara N, et al. Synergistic effect of vascular endothelial growth factor and basic fibroblast growth factor on angiogenesis in vivo. Circulation. 1995 Nov 1;92(9 Suppl):|l365-71.
14. Mauro A. Satellite cell of skeletal muscle fibers. J Biophys Biochem Cytol. 1961 Feb;9:493-5.

15. Menasché $P$, Hagège AA, Vilquin JT, Desnos M, Abergel E, Pouzet B, et al. Autologous skeletal myoblast transplantation for severe postinfarction left ventricular dysfunction. J Am Coll Cardiol. 2003 Apr 2;41(7):1078-83.

16. Dib N, Michler RE, Pagani FD, Wright S, Kereiakes DJ, Lengerich $\mathrm{R}$, et al. Safety and feasibility of autologous myoblast transplantation in patients with ischemic cardiomyopathy: four-year follow-up. Circulation. 2005 Sep 20;112(12):1748-55.

17. Menasché P, Alfieri O, Janssens S, McKenna W, Reichenspurner $\mathrm{H}$, Trinquart $\mathrm{L}$, et al. The Myoblast Autologous Grafting in Ischemic Cardiomyopathy (MAGIC) trial: first randomized placebo-controlled study of myoblast transplantation. Circulation. 2008 Mar 4;117(9):1189-200.

18. Antman EM. Coronary care medicine: it's not your father's CCU anymore. Trans Am Clin Climatol Assoc. 2004;115: 123-34.

19. Dimmeler S, Zeiher AM. Cell therapy of acute myocardial infarction: open questions. Cardiology. 2009;113(3):155-60.

20. Larochelle A, Vormoor J, Hanenberg $H$, Wang JC, Bhatia M, Lapidot $T$, et al. Identification of primitive human hematopoietic cells capable of repopulating NOD/SCID mouse bone marrow: implications for gene therapy. Nat Med. 1996 Dec;2(12): 1329-37.

21. Michallet M, Philip T, Philip I, Godinot H, Sebban C, Salles $G$, et al. Transplantation with selected autologous peripheral blood CD34+Thy1+ hematopoietic stem cells (HSCs) in multiple myeloma: impact of HSC dose on engraftment, safety, and immune reconstitution. Exp Hematol. $2000 \mathrm{Jul} ; 28(7)$ : 858-70.

22. Kawashima I, Zanjani ED, Almaida-Porada G, Flake AW, Zeng H, Ogawa M. CD34+ human marrow cells that express low levels of Kit protein are enriched for long-term marrowengrafting cells. Blood. 1996 May 15;87(10):4136-42.

23. Pittenger MF, Mackay AM, Beck SC, Jaiswal RK, Douglas R, Mosca JD, et al. Multilineage potential of adult human mesenchymal stem cells. Science. 1999 Apr 2;284(5411): 143-7.

24. Dominici M, Le Blanc K, Mueller I, Slaper-Cortenbach I, Marini F, Krause D, et al. Minimal criteria for defining multipotent mesenchymal stromal cells. The International Society for Cellular Therapy position statement. Cytotherapy. 2006;8(4):315-7.

25. Castro-Malaspina H, Gay RE, Resnick G, Kapoor N, Meyers $P$, Chiarieri D, et al. Characterization of human bone marrow fibroblast colony-forming cells (CFU-F) and their progeny. Blood. 1980 Aug;56(2):289-301.

26. Tang YL, Zhao Q, Zhang YC, Cheng L, Liu M, Shi J, et al. Autologous mesenchymal stem cell transplantation induce VEGF and neovascularization in ischemic myocardium. Regul Pept. 2004 Jan 15;117(1):3-10.

27. Arai F, Hirao A, Suda T. Regulation of hematopoiesis and its interaction with stem cell niches. Int J Hematol. 2005 Dec;82(5):371-6.

28. Furness SGB, McNagny K. Beyond mere markers: functions for CD34 family of sialomucins in hematopoiesis. Immunol Res. 2006;34(1):13-32. 
29. Ferreri NR, Escalante BA, Zhao Y, An SJ, McGiff JC. Angiotensin II induces TNF production by the thick ascending limb: functional implications. Am J Physiol. 1998 Jan;274 (1 Pt 2):F148-55.

30. Mezey E, Chandross KJ, Harta G, Maki RA, McKercher SR. Turning blood into brain: cells bearing neuronal antigens generated in vivo from bone marrow. Science. 2000 Dec 1;290(5497):1779-82.

31. Lagasse E, Connors H, Al-Dhalimy M, Reitsma M, Dohse $\mathrm{M}$, Osborne L, et al. Purified hematopoietic stem cells can differentiate into hepatocytes in vivo. Nat Med. 2000 Nov;6(11):1229-34.

32. Orlic D, Kajstura J, Chimenti S, Bodine DM, Leri A, Anversa $P$. Transplanted adult bone marrow cells repair myocardial infarcts in mice. Ann N Y Acad Sci. 2001 Jun; 938:221-9; discussion 229-30.

33. Fukuhara S, Tomita S, Yamashiro S, Morisaki T, Yutani C, Kitamura S, et al. Direct cell-cell interaction of cardiomyocytes is key for bone marrow stromal cells to go into cardiac lineage in vitro. J Thorac Cardiovasc Surg. 2003 Jun;125(6):1470-80.

34. Makino S, Fukuda K, Miyoshi S, Konishi F, Kodama H, Pan J, et al. Cardiomyocytes can be generated from marrow stromal cells in vitro. J Clin Invest. 1999 Mar;103(5):697-705.

35. Toma C, Pittenger MF, Cahill KS, Byrne BJ, Kessler PD. Human mesenchymal stem cells differentiate to a cardiomyocyte phenotype in the adult murine heart. Circulation. 2002 Jan 1;105(1):93-8.

36. Sussman MA, Murry CE. Bones of contention: marrow-derived cells in myocardial regeneration. J Mol Cell Cardiol. 2008 Jun;44(6):950-3.

37. Mangi AA, Noiseux N, Kong D, He H, Rezvani M, Ingwall JS, et al. Mesenchymal stem cells modified with Akt prevent remodeling and restore performance of infarcted hearts. Nat Med. 2003 Sep;9(9):1195-201.

38. Tse WT, Pendleton JD, Beyer WM, Egalka MC, Guinan EC. Suppression of allogeneic T-cell proliferation by human marrow stromal cells: implications in transplantation. Transplantation. 2003 Feb 15;75(3):389-97.

39. Bartholomew A, Sturgeon C, Siatskas M, Ferrer K, Mclntosh K, Patil S, et al. Mesenchymal stem cells suppress lymphocyte proliferation in vitro and prolong skin graft survival in vivo. Exp Hematol. 2002 Jan;30(1):42-8.

40. Le Blanc K, Tammik L, Sundberg B, Haynesworth SE, Ringdén $O$. Mesenchymal stem cells inhibit and stimulate mixed lymphocyte cultures and mitogenic responses independently of the major histocompatibility complex. Scand J Immunol. 2003 Jan;57(1):11-20.

41. Traverse JH, Henry TD, Pepine CJ, Willerson JT, Zhao DX, Ellis SG, et al. Effect of the use and timing of bone marrow mononuclear cell delivery on left ventricular function after acute myocardial infarction: the TIME randomized trial. JAMA. 2012 Dec 12;308(22):2380-9.
42. Traverse JH, Henry TD, Ellis SG, Pepine CJ, Willerson JT, Zhao DX, et al. Effect of intracoronary delivery of autologous bone marrow mononuclear cells 2 to 3 weeks following acute myocardial infarction on left ventricular function: the LateTIME randomized trial. JAMA. 2011 Nov 16;306(19):2110-9.

43. Jeevanantham V, Butler M, Saad A, Abdel-Latif A, ZubaSurma EK, Dawn B. Adult bone marrow cell therapy improves survival and induces long-term improvement in cardiac parameters: a systematic review and meta-analysis. Circulation. 2012 Jul 31;126(5):551-68.

44. Dawn B, Stein AB, Urbanek K, Rota M, Whang B, Rastaldo $R$, et al. Cardiac stem cells delivered intravascularly traverse the vessel barrier, regenerate infarcted myocardium, and improve cardiac function. Proc Natl Acad Sci U S A. 2005 Mar 8;102(10):3766-71.

45. Messina E, De Angelis L, Frati G, Morrone S, Chimenti S, Fiordaliso $\mathrm{F}$, et al. Isolation and expansion of adult cardiac stem cells from human and murine heart. Circ Res. 2004 Oct 29;95(9):911-21.

46. Urbanek K, Quaini F, Tasca G, Torella D, Castaldo C, NadalGinard B, et al. Intense myocyte formation from cardiac stem cells in human cardiac hypertrophy. Proc Natl Acad Sci U S A. 2003 Sep 2;100(18):10440-5.

47. Anversa P, Kajstura J, Leri A, Bolli R. Life and death of cardiac stem cells: a paradigm shift in cardiac biology. Circulation. 2006 Mar 21;113(11):1451-63.

48. Lanza R, Moore MA, Wakayama T, Perry AC, Shieh JH, Hendrikx J, et al. Regeneration of the infarcted heart with stem cells derived by nuclear transplantation. Circ Res. 2004 Apr 2;94(6):820-7.

49. Anversa P, Rota M, Urbanek K, Hosoda T, Sonnenblick EH, Leri A, et al. Myocardial aging--a stem cell problem. Basic Res Cardiol. 2005 Nov;100(6):482-93.

50. D'Alessandro DA, Kajstura J, Hosoda T, Gatti A, Bello $\mathrm{R}$, Mosna F, et al. Progenitor cells from the explanted heart generate immunocompatible myocardium within the transplanted donor heart. Circ Res. 2009 Nov 20;105(11):1128-40.

51. Davis DR, Zhang Y, Smith RR, Cheng K, Terrovitis J, Malliaras $\mathrm{K}$, et al. Validation of the cardiosphere method to culture cardiac progenitor cells from myocardial tissue. PLoS One. 2009 Sep 25;4(9):e7195.

52. Malliaras K, Marbán E. Cardiac cell therapy: where we've been, where we are, and where we should be headed. $\mathrm{Br}$ Med Bull. 2011;98:161-85.

53. Smith RR, Barile L, Cho HC, Leppo MK, Hare JM, Messina $E$, et al. Regenerative potential of cardiosphere-derived cells expanded from percutaneous endomyocardial biopsy specimens. Circulation. 2007 Feb 20;115(7):896-908. 